\title{
Insight Into Role of Transformaional Leadership in Cost Containment in Healthcare in Ksa
}

Randa Khirfan, Aniza Abd Aziz

To Link this Article: http://dx.doi.org/10.6007/IJARBSS/v12-i1/12327

DOI:10.6007/IJARBSS/v12-i1/12327

Received: 05 November 2021, Revised: 07 December 2021, Accepted: 28 December 2021

Published Online: 24 January 2022

In-Text Citation: (Khirfan \& Aziz, 2022)

To Cite this Article: Khirfan, R., \& Aziz, A. A. (2022). Insight Into Role of Transformaional Leadership in Cost Containment in Healthcare in Ksa. International Journal of Academic Research in Business and Social

Sciences, 12(1), 2657-2672.

\section{Copyright: (c) 2022 The Author(s)}

Published by Human Resource Management Academic Research Society (www.hrmars.com)

This article is published under the Creative Commons Attribution (CC BY 4.0) license. Anyone may reproduce, distribute, translate and create derivative works of this article (for both commercial and non0-commercial purposes), subject to full attribution to the original publication and authors. The full terms of this license may be seen at: http://creativecommons.org/licences/by/4.0/legalcode

\section{Vol. 12, No. 1, 2022, Pg. $2657-2672$}

Full Terms \& Conditions of access and use can be found at http://hrmars.com/index.php/pages/detail/publication-ethics 


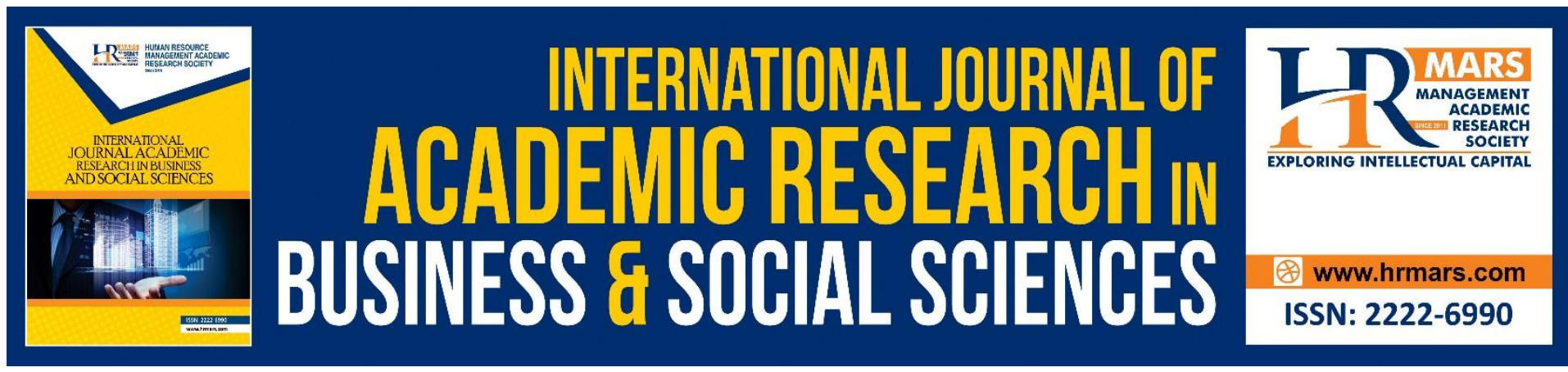

\title{
Insight Into Role of Transformaional Leadership in Cost Containment in Healthcare in Ksa
}

\author{
Randa Khirfan, Aniza Abd Aziz \\ Faculty of Medicine, Universiti Sultan Zainal Abidin, Malaysia
}

\begin{abstract}
Transformational leadership (TFL) is an influential leadership approach has strong impact on several causes of cost inflation in healthcare. This study has been carried out to determine the relationship between transformational leadership and cost containment. This study conducted in two secondary hospitals in the Northern Border in Saudi Arabia. 60 subjects of staff who meet the eligibility criteria participated in the study.

Factor analysis, mean, SD, and regression have been used for data analysis. The findings showed significant effect of TFL on cost containment. The study recommends training of hospital stakeholders in particular as a mean of creating cost effective work environment.
\end{abstract}

\section{Introduction}

\section{Study Problem}

Health sector in Saudi Arabia, like other health sectors around the world, face many challenges that effect expenditure of healthcare system. There is a substantial increase in cost of health service. However, researches focus on managing some factors responsible for increment in healthcare expenditure as employee satisfaction, burnout, performance, retention, satisfaction, and reduction of medical errors. TFL is promised effective leading approach utilized for treating the spending problem indirectly through controlling recruitment and medical errors cost. The indirect positive association between TFL and cost containment provide policy makers in health sector with a new unique perspectives to handle the problem of dramatically growing health cost.

\section{Main Terminologies}

Transformation leadership, Cost containment, and Health care.

Research question: How strong is the effect of TFL in influencing cost containment in healthcare?

Research hypothesis: TFL has statistical significant effect on cost containment in healthcare.

\section{Significance of Study}

In this challenging situation, this study provides efficient method to assess the current competency in the application of transformational leadership as an influencing factor on cost containment in the healthcare in the Kingdom of Saudi Arabia. Remarkable mitigation of the inflated health care expenses can't be accomplished and succeeded unless innovative 
solution based on humans' capital as a sustainable source of investment is considered. Proper Implementation of TFL enables decision makers and healthcare planners to identify the root causes and propose more cost effective health care reforms plans.

Incremental surplus in health care expenditure is a multi-factorial problem threatens governments worldwide and its implication is more seriously impressing in unstable economy countries. It has become challenging for hospitals to survive, and to make a profit while providing high quality care under compressing economic pressure. Recently, application of transformational leadership style is proposed as a treating approach for the current spiral cost problem. There are several factors that impact the variable and constant cost of health care institutions such as professionals' retention, burnout, satisfaction, and underutilization of evidenced based practice (EBP), level of performance, and malpractice and medical errors. All these influential factors have indirectly increased spending due expand the necessity for recruiting new staff, and cost of complication resulted from medical malpractice. TFL style has the combating potential outcomes for the inflating health care cost through handling of burnout, retention, satisfaction, and medical errors. The health economy professionals, administrative, and stakeholders in health sector are the key players should take the initiate to manage this challenge (Choi et al; 2016). The core point presented in this cross sectional study is the achievability of fulfilling the targeted population needs by efficient leadership to maximize use of available capitals despite all impressing obstacles and negatives.

\section{Literature Review}

Transformational Leadership style (TFL) is motivating followers to achieve special purposes, inspiring sense of vision and purpose. It has four dimensions suggested by Bass Avolio; idealized influence, inspirational appeal, intellectual stimulation and individualized consideration (Hamdani, 2018). Idealized influence means leaders enjoy being loyal, trust, and admire followers, act as a role model who emulates followers and internalizing ideas. Inspirational motivation reflects leaders' capacity to motivate employee achievement of high expectation to fulfil the organization goals through providing a clear vision. Intellectual stimulation reflects encouraging staff to be innovative problem solvers, encourage creativity and offering learning opportunities. And individualized consideration is applied through attention and enhancing employee self-development and supportive relationship by sharing ideas and recognition. A systematic review revealed TFL can inspire qualities as confidence, respect, and loyalty to organization vision that strengthen productivity, satisfaction, and morale. TFL leaders are the most powerful and highly capable leading style to handle spending related variables. TFL provide a precious opportunity for instilling future goals, motivating cost effective practice, and encouraging professional development (Hamdani, 2018).

Employees satisfaction enhanced by TFL leaders lead to reduction in adverse events. Additionally, leadership style affects quality of healthcare provision and Patient safety culture. By empowering staff, TFL increase staff stability and reduce burnout. Consequently, effective leadership that supports retaining experienced professionals can indirectly decrease mortality rates (Sfantou et al., 2017). TFL is a powerful remedy of burnout by facilitating positive job attitudes in many industries including healthcare.

Several studies revealed the positive impact of transformation leaders on staff retention. 197 case managers working in child protective service was surveyed in non-experimental study; results acknowledged a negative correlation between TFL and job burnout. Hiring TFL leaders in child welfare settings was strongly recommended to combat burnout (Rittschof, 2016). Because of the participative style of transformational leadership; it is the most effective style 
for preserving staff. Transformational leaders act by instilling an insight on the best cost saving mechanisms for the institute and customers. Using effective communication enables retaining employees and customers and then lowers marketing and recruitment expenses. By inspiring goals and coaching, the employee skills will improve to the maximum potential and superior performance fostered (Samad, 2012).

Staff retention has become a priority for healthcare managers because of endemic and proliferating health care professional shortage. Leaders' recognition might indirectly manage professional shortage by enhancing retention. A study in USA found inverse relationship between transformational leadership and turnover. The direct and indirect cost of turnover threatening organization could be minimized by the adverse impact of TFL (Long \& Thean, 2011; Mouhamadou et al., 2016). A systematic research review targeted to determine whether patient safety and burnout are correlated to healthcare professionals' wellbeing showed that poor wellbeing and burnout are significantly associated with poor patient safety and quality patient care. Therefore, work environment that fosters wellbeing and lower rate of burnout is more capable for provision of higher patient safe care (Hall et al., 2016).

A survey conducted to investigate the influence of leadership style on organization commitment and retention of 2019 nurses and nursing managers in Saudi Arabia showed confirming results. Transformational leadership found to be a powerful predictor of organisational commitment. The study provides insight into the type of leadership that is best suited to the dynamic and changing health care system in Saudi Arabia (Al-Yami et al., 2018). Another study support the positive effect of TFL carried out in Malaysia where low retention of nursing staff related to a lack of job satisfaction. This query investigated the influence of transformational leadership revealed its positive effect on job satisfaction mediated by empowerment. Hence, TFL could be implemented as a method of enhancing job satisfaction (Choi et al., 2016).

Kwah (2016) support an inverse relationship between burnout and medical errors. Burnout affecting internal medicine residents negatively and increase their possibility of medical errors. A single institution observational cohort study aim to evaluate the impact of burnout revealed Physicians have lower burnout score have lower prescription errors. Cross-sectional analysis to investigate the effect of 2084 nurse burnout on quality patient care and adverse events in Thai 94 community hospitals. All three subscales of the Maslach Burnout Inventory were associated with increased reporting of fair or poor quality of care, patient falls, medication errors, and infections. increasing of emotional exhaustion score was associated with a 2.63 times increase in reporting of fair or poor quality care, a $30 \%$ increase in patient falls, a $47 \%$ increase in medication errors, and a $32 \%$ increase in infection (Nantsupawat et al., 2015).

TFL leaders have the capacity to boost quality practice, job satisfaction, and patient safety. Nursing leadership has a double responsibility manifested by provision of quality care and accomplishment of institutional target. TFL leaders' motivate and support quality professional practice and patient safety. In Ontario, 378 acute care nurses randomly selected for cross sectional study exploring the influence of TFL on job satisfaction and patients' safety. It was found that TFL had strongly impacted the workplace empowerment, which in turn reflected positively on job satisfaction and reduction of adverse events (Boamah et al., 2018). A longitudinal quantitative study design over 18 months for Danish elderly care showed the effect of TFL on the psychological wellbeing of employees and job satisfaction. TFL action explained by affecting perceptions of work-life conflict and ultimately adoption is highly suggested (Munir et al., 2012). A research implemented to determine the association 
between transformational leadership and 150 employees' job satisfaction at private universities in Bosnia and Herzegovina. The findings determined that a moderate, positive and significant relationship exists between the dimensions transformational leadership and employees' job satisfaction (Bayram \& Dinç, 2015). To evaluate the effect of transformational and transactional leadership styles of head nurses on the job satisfaction of staff nurses in critical care units (CCU) of a tertiary care hospital at Aseer Central Hospital (ACH), Abha, Saudi Arabia. Nurses working under leaders with a TFL style demonstrated significantly $(p<0.05)$ higher job satisfaction. The study emphasized the importance of TF style of head nurses for increasing staff nurses' job satisfaction. It is suggested that nurse leaders should be trained in TF style of leadership and provided more support and training for effective management of CCU (Alshahrani1 \& Baig, 2016).

The present descriptive study aims to investigate the impact of leadership styles on job satisfaction and to see if perceived organizational politics has a mediating role or not. Research finding revealed that transformational leadership has a positive impact on job satisfaction and transactional leadership has a negative impact on job satisfaction. Findings also suggest that, perceived organizational politics partially mediate the relationship between both leadership styles and job satisfaction (Saleem, 2015).

Another Study by Alotaibi et al (2015) confirmed the mediation effect that organization climate play between TFL and patient safety. Organizational climate indicates the attitude workers have towards organizations like trust level and morale, rewards equity, leadership credibility, and change resistance (Ngo et al., 2009). Transformational leaders promote their associate's sense of purpose that goes beyond the reward for effort exchange (Bass \& Avolio, 1997).

An evaluation study of how transformational leadership behaviour is associated with patient safety culture in a hospital context found similar findings. Transformational behaviour would positively influence the frequency of events reported by staff on the front line of service provision. As a result, TFL was a significant predictor of the reporting frequency of safety events, as perceived by medical directors (Hillen et al., 2017).

Transformational leadership utilized in teaching of safe medication management by lowering the prevalence of adverse drug events (ADEs) and medication-related hospitalisations. Role modelling that represent idealized influence is the relevant TFL dimension to safety education. Inspirational motivation strengthens learners' commitment. Intellectual stimulation motivates improvement and change process. Individualised consideration assists goals and practice development, and patients' outcomes. As an approach of medication safety education, Transformational leadership focus is working on abilities and assisting learning culture, and mentoring role of educators. TFL act by stimulate creativity and ethical behaviour for students (Vaismoradi et al., 2016). Additionally, a report examines influence of quality practice in categorization and reduction of preventable medication-related hospital admissions in rural and urban areas in Hawaii. Systematic pharmacists' evaluation of readmission cases for reason and possibility of admission prevention found that twenty-six per cent were classified as preventable medication related readmission (Pellegrin et al., 2017).

Cross-sectional study used survey data from 246 RNs working in a Magnet examine if leadership style and unit climate predict safety climate, and effect of safety climate on nurses' safe medication practices. According to the Institute of Medicine, safety climate is a prerequisite to safety practices. The research revealed that Leadership style and unit climate predicted $20 \%$ to $50 \%$ of variance on all safety climates indirectly (Amany et al., 2017). 
TFL leaders can decrease personnel cost and medical supplies cost. Measuring the performance of the supply chain is fundamental to identify and address deficiencies in the logistics activities, and considered an important input for managers to take a decision. Inventory management and supplies distribution are key operational activities for healthcare. The medical supplies consume the second largest share of health expenditure after personnel cost. Good supply chain performance lead to more efficient outcomes presented in improving patient safety and care quality (Amin et al., 2019). Organizations investment in human resources is the most advantageous at long term. Improving personnel performance and competitiveness, and enhance the achievement measurement (Frixou \& Charalambous, 2016).

A study investigate TFL impact on team performance, innovation, and psychological empowerment in UAE for 182 subjects revealed higher significant positive TFL impact on team performance than transactional style mediated by psychological empowerment (Rao \& Kareem, 2015).

This cross-sectional study in 2016 examined the effect of transformational leadership on employees' productivity in two teaching hospitals in Iran where 254 participants from educational and medical Sciences showed a positive impact of TFL on employees' productivity. Transformational leaders are inspiring; energetic, enthusiastic, and passionate (Vatankhah et al., 2017). The High level of adaptive capacity from adaptive leadership raises employee potential for goals accomplishment. Multisite Qualitative Study revealed the impact of adaptive leadership on prevention of Healthcare-Associated Infection (Anderson et al., 2015).

TFL has a core role in managing malpractice. A descriptive study investigating the most commonly used medication in Saudi Arabia from 2010 to 2015 showed the use of antibiotics and analgesics have the highest percentage followed by proton pump inhibitors and antidiabetics respectively. The root causes of overutilization were the over-prescription, and malpractice. National guide for diagnosis and treatment, and adhering to dispensing system and reviewing of pharmaceutical policies are recommended (AlKhamees et al., 2018).

Some researches argued the implicit role of TFL in lowering the cost spending by strengthening the preventive medicine. Creative and collaborative strategies are utilized by nursing leaders to strengthen the preventive practices. Engaging leadership skills in clinical setting assists implementing research finding in study area (Muhrer \& Jill, 2017). Strengthening the leadership behaviours can improve the quality of outcomes in long-term care settings and decrease the incidence of pressure ulcers. A study advocate practice based interdisciplinary teamwork and TFL for prevention of pressure ulcer utilization to guide patients care. Strong leadership of nurse is crucial for stabilization of workforce, improving potential, and sustaining of prevention standards of pressure ulcer (Kennerly et al, 2012). Research investigation implemented to determine if organizational culture (OC) and behavioural attitudes influence the infection prevention control practices in hospitals. Changing $\mathrm{OC}$ is promising approach because comprehending perception of customers and staff directs the staff behaviour to be more legitimate and desirable (De Bono et al., 2014). People expect healthcare workers to provide the best available evidence. Transformational nursing leadership enable sustainability of evidenced based practice (EBP). Access to information, resources, support, creating expectations and empowerment are essential TFL competences for applying EBP (Kouzes and Posner, 2011). One important barrier behind underutilization, adoption and implementation of EBP is the perceived burden of usage that ultimately decreases the associated favourable client outcomes. Transformational leadership 
and empowerment are negatively and significantly associated with perceived burden of EBPs through its association with demoralizing climates (Brimhall et al., 2016). Researchers merge the principles of evidence-based practice with cost-effectiveness to provide accepted care consuming least cost. More efforts are needed to change the current policies that lead to waste. Health reform plans should change the regulations that resist using of less expensive health treatment. Consequently, it's essential to redistribute the available human power and modify the strategies of selection and staff recruitment. Hiring process must be applied with foresight and wisdom. The recruiters require accurate planning to estimate the forecasting and long-term need for new employees and the estimated cost for recruitment. The quality and qualification of the required staff also should be predetermined and cost effectiveness to be considered while recruiting (Gusdorf, 2008). As a result, only highly qualified candidates will be selected to alleviate the problem of shortage.

Idealized influence and inspirational motivation dimensions of transformational leaders who internalizing goals and providing information and ideas might be helpful in cost saving. Health professionals target containing expenditure and have sufficient information are capable to achieve cost efficiency in operating room by better management of disposable and reusable supplies. Disseminating supply prices and wastage information would change surgeon and nurses behaviour. Prospective French study found that wasted supplies represented up to $20.1 \%$ of the total cost allocated to surgical supplies in OR (Chasseignea et al., 2018).

Cost-containment

Cost-containment measures are any actions that lower current spending, investment, or debt levels (Oliver, 2018). The tried means of rationalization as reduction in overtime and temporary labours and cost cutting are not beneficial or effective any more (Oliver, 2018). Healthcare systems are under severe pressure due to aging populations, rising costs of medical technologies, budget austerity and increasing expectations. Focusing on productivity improvement is promised mean for tackling cost pressure.

The US and UK have the highest average management scores, which we think may be due to relatively politically independent appointment of hospital leaders and stronger accountability mechanisms (Bloom et al., 2014).

In Australia; resources allocation projects involved removal, or restriction of some practices were forced by quality and safety issues, evidence-based practice, and cost saving requirements. A new program of Sustainability in Health care by Allocating Resources Effectively in local hospitals in Australia relates resources allocation decision to administrative and saving issues. Measuring resource savings is difficult, measured by patients waiting for beds, clinic appointments or surgery (Harris et al., 2017).

To determine the cost effectiveness of needle arthroscopy (NA) and magnetic resonance imaging (MRI) as a means of diagnosis and treatment of meniscal tears over two years from patient point of view. Global knee injury and osteoarthritis outcome score (KOOS) was used in evaluation process. NA was cost effective and with similar outcomes (Amin et al., 2019).

\section{Research Methodology}

Study Design and Population

A quantitative cross sectional study design. Population is health care professionals from all clinical categories in two secondary hospitals in the Northern Borders in the Kingdom of Saudi Arabia. 
Sampling Method and size

Participants will be five staff categories; doctors and administrative personnel having medical background, nurses, pharmacists, and allied health sciences. Systematic random sampling method is used for subjects' selection. 60 respondents of the target group met the eligibility criteria completed the questionnaire.

\section{Inclusion and Exclusion Criteria}

Permanent staff, having more than one year experience in clinical field (hospital), older than 20 years, and having at least diploma degree were included. Whereas administrative staff not having medical background, have less than one year experience, age less than 20 , temporary staff (locum, visitors, and part-time), and scientific qualification less than diploma.

Instrument

Instrument consisted of three sections; sociodemographic data including gender, speciality, educational level, and number of experience years. The second part is 6 items reflecting the four TFL dimensions adapted from Multifactor Leadership Questionnaire developed by Bass Avolio (1995) that concerned with measuring how followers percieve their superiors transformational leadership skills. Second part is eight questions emerged from the relvant literatuer indicating cost containment practices as percieved by employees. Ten point likert scale was used to measure all scale items; where one indicate strongly disagree, and ten indicate strongly agree. The questionnaire items shown in table 1

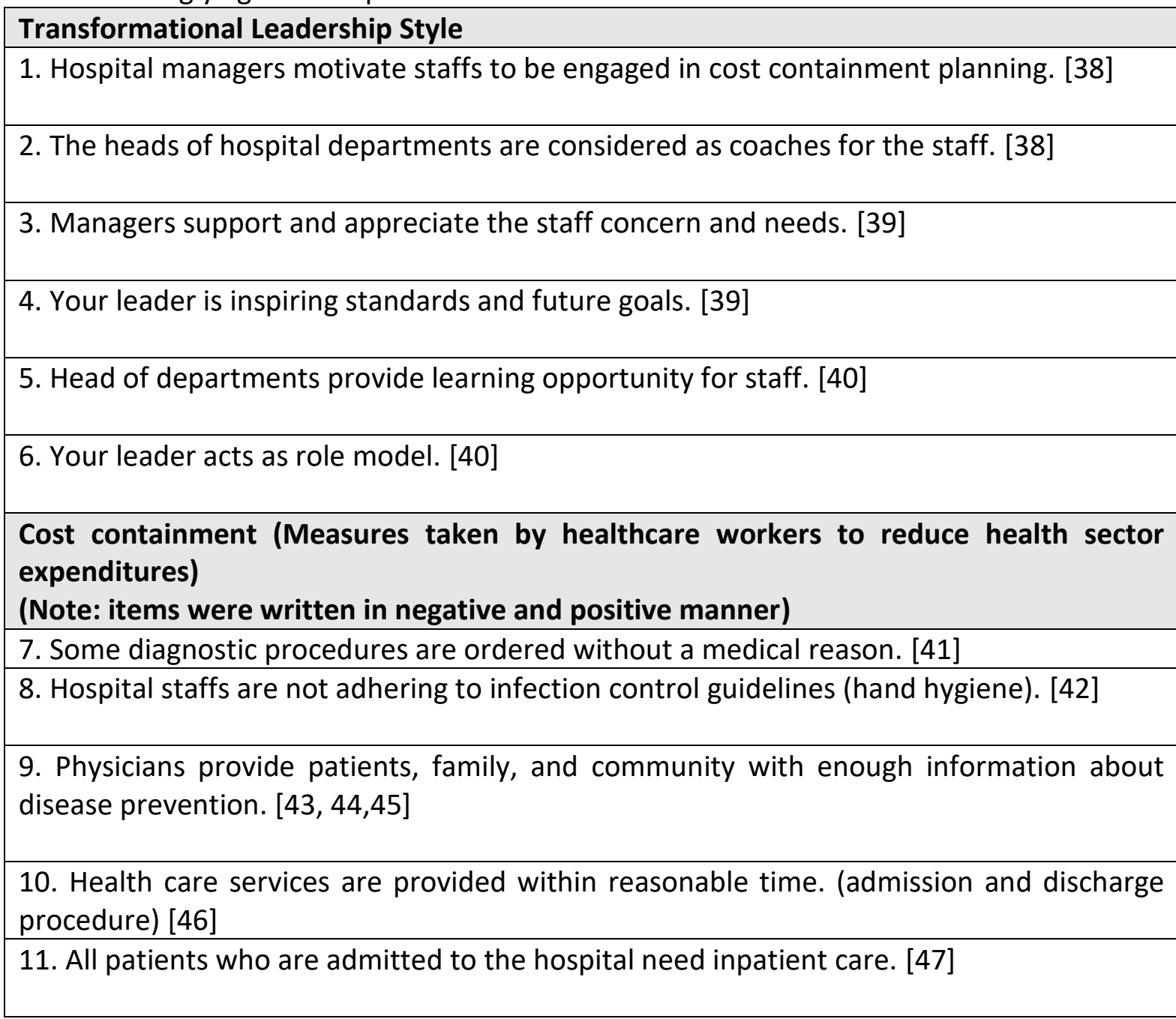


12. The staff follows the admission procedure as explained in the admission policy. [48]

13. The hospital suffers from continuous turnover of the staff. [49]

14. Some patients stay in hospital longer than the expected length of stay according to their health condition. $[50,51]$

Validity and reliability of the questionnaire: Six reviewers from academic field who are specialized as health economists or hospital administrative judged the instrument validity (content validity is achieved). Bresilienne method for translation used to translate the items from English to Arabic, and back to English. After that, the construct validity was checked by conducting exploratory factor analysis. Reliability test was conducted for the two variables and presented by Cronbach alpha value.

3.5 Ethical Consideration: Ethical approval for conducting this study has to be obtained.

3.6 Data collection method: questionnaire of cost containment instrument consists of 14 items was distributed to the study participants. The study participants were explained about the study purpose, importance of data, and anonymity.

\section{Statistical Analysis and Results}

The descriptive analysis of the data was analysed using SPSS (v.23) software package. All demographic groups including gender, age, education, and experience who recorded the highest TFL were the same groups have the highest cost containment mean score. Except for profession, were pharmacists possessing the highest TFL and allied health sciences possess the highest cost containment score.

GENDER

\begin{tabular}{|c|l|l|l|l|}
\hline & $\begin{array}{l}\text { Frequenc } \\
\mathrm{y}\end{array}$ & Percent & TFL mean & $\begin{array}{l}\text { Cost containment } \\
\text { mean }\end{array}$ \\
\hline male & 31 & 51.7 & 7.6759 & 7.1806 \\
female & 29 & 48.3 & 6.5758 & 6.6477 \\
Total & 60 & 100.0 & 7.0708 & 6.8875 \\
\hline
\end{tabular}

$51.7 \%$ of the respondents were male. Gender majority group was male who has higher TFL score; 7.6 and higher cost score: 7.1 than female who has 6.5 TFL score and 6.6 cost saving practice score.

AGE
\begin{tabular}{|c|l|l|l|l|}
\hline & $\begin{array}{l}\text { Frequenc } \\
y\end{array}$ & Percent & TFL mean & $\begin{array}{l}\text { Cost containment } \\
\text { mean }\end{array}$ \\
\hline $20-30$ & 9 & 15.0 & 5.6667 & 6.3438 \\
$31-40$ & 38 & 63.3 & 7.2816 & 6.9914 \\
$41-50$ & 12 & 20.0 & 6.9167 & 6.6250 \\
$51-60$ & 1 & 1.7 & 7.5000 & 7.6250 \\
Total & 60 & 100.0 & 7.0708 & 6.8875 \\
\hline
\end{tabular}


Regarding age group distribution; 63\% were within 31-40 years old. Age group (51-60) reported the highest mean score of TFL 7.5 and highest mean score of cost containment 7.6, followed by majority age group constituted 63\% (31-40) which has 7.2 mean score of TFL practicing and cost containment score: 6.9

PROFESSION

\begin{tabular}{|l|l|l|l|l|}
\hline & Frequency & Percent & TFL mean & $\begin{array}{l}\text { Cost containment } \\
\text { mean }\end{array}$ \\
\hline physician & 11 & 18.3 & 6.9524 & 6.7321 \\
nursing & 23 & 38.3 & 7.1739 & 6.8587 \\
pharmacist & 7 & 11.7 & 8.1111 & 6.5000 \\
adminstrative & 7 & 11.7 & 5.0000 & 7.0000 \\
allied health & 12 & 20.0 & 6.9667 & 7.4250 \\
sciences & & & & \\
Total & 60 & 100.0 & 7.0708 & 6.8875 \\
\hline
\end{tabular}

Profession majority group was nurses at $38.3 \%$ have TFL score 7.1 and cost score: 6.8 . While and it is nearly same values recorded for physicians. A pharmacist is the profession recorded the highest TFL score: 8.1, they recorded relatively low rate of cost saving: 6.5 . Allied health sciences professions showed highest cost containment score: 7.4 and TFL score: 6.9. Surprisingly; findings obtained regarding the TFL score for administrators demonstrates the lowest TFL mean score: 5.

EDUCATION
\begin{tabular}{|l|l|l|l|l|}
\hline & Frequenc \\
& $y$ & Percent & TFL mean & $\begin{array}{l}\text { Cost } \\
\text { containment } \\
\text { mean }\end{array}$ \\
\hline diploma & 15 & 25.0 & 5.7424 & 6.0227 \\
bachelor & 35 & 58.3 & 7.9638 & 7.2554 \\
master & 8 & 13.3 & 6.7500 & 7.5938 \\
PHD & 2 & 3.3 & 4.7500 & 6.0000 \\
Total & 60 & 100.0 & 7.0708 & 6.8875 \\
\hline
\end{tabular}

In term of academic level; master degree staff reported the highest cost saving score: 7.5, followed by bachelor holders who constitute $58.3 \%$ and have 7.9 TFL score and 7.2 cost score.

EXPERIENCE

\begin{tabular}{|c|l|l|l|l|}
\hline Experience & $\begin{array}{l}\text { Frequenc } \\
\mathrm{y}\end{array}$ & Percent & TFL mean & $\begin{array}{l}\text { Cost containment } \\
\text { mean }\end{array}$ \\
\hline $1-4$ & 6 & 10.0 & 4.0000 & 5.1250 \\
$5-9$ & 36 & 60.0 & 7.4038 & 7.1202 \\
$10-14$ & 12 & 20.0 & 6.4375 & 6.6563 \\
$15-20$ & 6 & 10.0 & 6.9667 & 6.4000 \\
Total & 60 & 100.0 & 7.0708 & 6.8875 \\
\hline
\end{tabular}


In term of work experience; $60 \%$ of the participants have 5-9 years' experience. Experience majority group was (5-9) constitutes $60 \%$ has highest TFL score; 7.4 and highest cost score; 7.1

The content validity was checked by conducting exploratory factor analysis. The first 6 items represent the four dimensions of transformational leadership. Factor extraction was done by using principle component analysis and the varimax was used for component rotation. Rotated component matrix of questions (loading) or estimate of the correlation between each variable and estimated component was done. Corrected item total correlation considered for TFL items adapted from Bass Avolio tool, and cost containment questions extracted from the literature.

The reliability Cronbach alpha test for TFL is: 0.827 and for cost containment is 0.58 . Durbin Watson test for auto-correlation between TFL and cost containment is 0.122 at significant level 0.01. Regression analysis was calculated to test the hypothesized relationship between dimensions of TFL and cost containment. The items of TFL dimensions were found to have positive significant relationship with cost containment dimension.

\section{Discussion}

The purpose in this study was to examine the perceptions of transformational leadership behavours and cost containment practices. The findings showed that Transformational leadership has a positive significant correlation with cost containment. Consequently, this study presented evidence to support adopting and implementing TFL in clinical area to accomplish cost saving practices. According to this result, the study hypothesis is supported. All groups demonstrated higher level of TFL reported higher compliance score of cost containment practices.

The results showed the age group (51-60) possess the highest score of TFL and the highest score of cost containment. The second highest score of TFL recorded for the age group (3140) and the second highest score of cost containment. A study to examine the relationship between transformational leadership and ratings of team performance revealed the relationship was positive when the leader was older than other team members, but nonsignificant when the leader's age was closer to the mean age of the team members (Eric Kearney, 2010). Older managers were received more consultation and prefer higher level of participation. Idealized influence was higher among older managers than younger managers and the other sub dimensions were the same between the two groups (Oshagbemi, 2004).

Education level is correlated to TFL score and cost containment score. Correlation between gender, age, and education and leadership styles for 290 members was investigated. Results indicated a small direct effect of age and larger and consistent effect resulted from the interaction of gender and education on leadership behaviour (Barbuto et al., 2007). Having bachelor's academic degree reflects higher transformational leadership than master degree holder and PHD holders. This is compatible with previous study findings that bachelor have a higher TFL level compared to master staff. In this study; PHD staff has the lowest degree of TFL, but another study found that PHD people indicated higher score than master degree people. The contradiction was higher rate of Idealized Influence and Inspirational Motivation sub-dimension that PHD holders have than that for MA holders, and similar rate of the Intellectual Stimulation and Individualized Consideration sub-dimension (Bernard \& Bass, 1999). 
Findings revealed male recorded higher mean score of TFL than female and higher score of cost containment. Contrary to earlier expectations, women leaders tend to be more transformational than their male counterparts (Stempel et al., 2015).

In a questionnaire study, 113 participants in Germany were asked to rate the probability of occurrence of a specific leadership behaviour for male and female leaders. As predicted, transformational leadership is believed to be more typical of female leaders. Nevertheless, inspirational motivation and idealized influence attributed are rated as being gender neutral. Implications regarding potential gender biases for selection, training, and performance appraisals of leaders are recommended (Stempel et al., 2015).

There is a difference between professions in term of TFL score and cost score. Pharmacists recorded the highest TFL score but relatively low cost containment. Allied health sciences showed the highest degree of cost containment. Confirmatory study declares a significant difference in the behaviour of transformational leaders of allied health sciences professions. The score of radiographers and podiatrists was consistently lower compared to other professions (Herman \& Gish, 2015). Administrative staff possesses comparably not high degree of transformational leadership. This might be due to following the criteria or seniority for holding administrative position. Gilley, 2003 stated that the selection process of department not grounded mainly on leadership knowledge, skills or abilities or may be based on their intellect, research abilities and renown in special area (Wylie et al., 2009).

Length of experience (5-9) reported highest TFL and the highest cost score. This is justified because experience less than 5 years is insufficient for professionals to decide the best cost effective option of treatment. Seniority of grade has a significant impact on the score of leadership behaviour ( $p<0.001$ ) (Wylie et al., 2009).

item 13 (The hospital suffers from continuous turnover of the staff) in the measuring scale get the lowest evaluation; 4.9 for physicians, 6.2 for nurses, 5.5 for administrators, 5 for allied health sciences, and 5 for pharmacists. This necessarily signifies the importance to evaluate the staff satisfaction and do root cause analysis of low rate of retention, and activate the role of utilization review committee and requesting criteria policy.

\section{Conclusion and Recommendations}

However, leadership knowledge, skills or abilities, possess the entire catalogue of leadership traits, these qualities do not necessarily equate to effective leadership and the wisdom that effective leadership requires (OlcumCetin \& FaydaKini, 2015) In advanced training of leaders has a significant effect on transformational behaviours $(p<0.001)$ (Herman \& Gish, 2015). To identify differences in the strength of nursing leadership according to the position title. Nursing positions of director and higher have strongest in leadership practices (Wylie et al., 2009).

Training is highly recommended for people responsible for dispensing or allocation such physicians, nurses, and pharmacists of supplies and resources. Causes of lowering the cost containment score for pharmacists should be studied further and treated. Administrators should be targeted for TFL training to enhance their managerial skills. They should be more careful to involve the spending and containment mechanisms in planning process and provide an access for frontline employees for prices information. Selection from different options and distribution of available resource shall consider cost effectiveness.

It's extremely important to keep monitoring of productivity, performance, and quality and patient safety indicators. Capability of retention and percentage of staff burnout are mandatory for root cause analysis and to be discussed at executive level. Special training 
courses for medical supply store and local purchase people, and specially pharmacists could be beneficial. Activation of the role of utilization review committee to identify the main sources of wasting. Human resources people are the mostly relevant for selection and recruitment of TFL leaders and instilling and encouraging the staff to pursue this mean of management to include all related parties. The core responsibility for quality specialist in curbing the expenses of medical treatment implied in doing periodic monitoring and controlling of all quality aspects contributed to inappropriate and controllable cost. To sum up, transformational leadership style, generally, is attainable through learning and training and has a positive effect on containing cost at northern borders.

\section{Limitations and Further Research}

This research is limited to only two secondary hospitals. Having small size of respondents is also limitation of this research. Involving other hospitals in data collection can provide stronger and more reliable findings. Moreover, Future studies should also focus on the private and governmental primary, secondary, and tertiary health care settings.

\section{References}

Hamdani, M. (2018). Learning how to be a transformational leader through a skill building, role-play exercise. The International Journal of Management Education, 16(1), 26-36. Retrieved from https://doi.org/10.1016/j.ijme.2017.11.003

Sfantou, D., Laliotis, A., Patelarou, A., Pistolla, D., Matalliotakis, M., \& Patelarou, E. (2017). Importance of Leadership Style towards Quality of Care Measures in Healthcare Settings:A Systematic Review. Healthcare, 5(73) Retrieved from doi:10.3390/healthcare5040073

Rittschof, K. R. (2016). The Influence of Transformational Leadership and Job Burnout on Child Protective Services Case Managers' Commitment and Intent to Quit. Journal of Social Service Research, 42(3)

Samad, S. (2012). The Influence of Innovation and Transformational Leadership on Organizational Performance. Procedia - Social and Behavioral Sciences, 57: 486 - 493 Retrieved from doi: 10.1016/j.sbspro.2012.09.1215

Long, C. S., \& Thean, L. Y. (2011). Relationship Between Leadership Style, Job Satisfaction and Employees' Turnover Intention: A Literature Review. Research Journal of Business Management, 5(3): 91-100

Mouhamadou, S., Ambroise, N., \& Rosa, O. (2016). Relationship between Transformational Leadership and Employee Retention among Healthcare Professionals in the United States. Business and Economic Research, 6(2) ISSN 2162-4860

Hall, L. H., Johnson, J., Watt, I., Tsipa, A., \& O'Connor, D. B. (2016). Healthcare Staff Wellbeing, Burnout, and Patient Safety: A Systematic Review. PLOS ONE 11(7). doi:10.1371/journal. pone.0159015

Al-Yami, M., Galdas, P., \& Watson, R. (2018). Leadership style and organisational commitment among nursing staff in Saudi Arabia. J Nurs Manag, 26:531-539.

Kwah, J., Weintraub, J., Fallar, R., \& Ripp, J. (2016). The Effect of Burnout on Medical Errors and Professionalism in First-Year Internal Medicine Residents. Journal of Graduate Medical Education, 8(4): 597-600.

https://doi.org/10.4300/JGME-D-15-00457.1 
Nantsupawat, A., Nantsupawat, R., Kunaviktikul, W., Turale DEd, S., \& Poghosyan, L. (2015). Nurse Burnout, Nurse-Reported Quality of Care, and Patient Outcomes in Thai Hospitals. Journal of nursing scholarship, 28(1): 83-90

Boamah, S. A., Laschinger, S. H. K., Wong, C., \& Clarke, S. (2018). Effect of transformational leadership on job satisfaction and patient safety outcomes. Nursing Outlook, 66(2): 180189

Munir, F., Nielsen, K., Garde, A. H., Albertsen, K., \& Carneiro, I. G. (2012). Mediating the effects of work-life conflict between transformational leadership and health-care workers' job satisfaction and psychological wellbeing. Journal of nursing management. Journal of Nursing Management, 20(4): 512-521

Bayram, H., \& Dinç, S. (2015). Role of Transformational Leadership on Employee's Job Satisfaction: the Case of Private Universities in Bosnia and Herzegovina. European Researcher, 93(4).

Alshahrani1, F. M., \& Baig, L. A. (2016). Effect of Leadership Styles on Job Satisfaction Among Critical Care Nurses in Aseer, Saudi Arabia. Journal of the College of Physicians and Surgeons Pakistan, 26(5): 366-370

Saleem, H. (2015). The impact of leadership styles on job satisfaction and mediating role of perceived organizational politics. Procedia - Social and Behavioral Sciences, 172: 563 569

Alotaibi, E. D., Yusoff, R. Z., Al-Swidi, A. K., Al-Matari, I. M., \& AlSharqi, O. Z. (2015). The Mediating Effect of Organizational Climate on the Relationship between Transformational Leadership and Patient Safety: A Study on Saudi Hospitals Mediterranean. Journal of Social Sciences, 6(2)

Hillen, H., Pfaff, H., \& Hammer, A. (2017). The association between transformational leadership in German hospitals and the frequency of events reported as perceived by medical directors. Journal of Risk Research, 20(4): 499-515

DOI: 10.1080/13669877.2015.1074935

Vaismoradi, M., Griffiths, P., Turunen, H., \& Jordan, S. (2016). Transformational leadership in nursing and medication safety education: a discussion paper. The journal of nusing management, 24(7): 970-980

Pellegrin, K. L., Lee, E., Uyeno, R., Ayson, C., \& Goo, R. (2017). Potentially preventable medication-related hospitalizations: A clinical pharmacist approach to assessment, categorization, and quality improvement. Journal of the American Pharmacists Association, $57711 \mathrm{e} 716$

Amany, F., Susan, T. G., Mary, K. A., \& Christopher, B. (2017). Do Leadership Style, Unit Climate, and Safety Climate Contribute to Safe Medication Practices?

The Journal of Nursing Administration, 47(1): 8-15 doi: $10.1097 /$ NNA.0000000000000430

Amin, N., Mclntyre, L., Carter, T., Xerogeanes, J., \& Voigt, J. (2019). Cost-Effectiveness Analysis of Needle Arthroscopy Versus Magnetic Resonance Imaging in the Diagnosis and Treatment of Meniscal Tears of the Knee. The Journal of Arthroscopic and Related Surgery, 35(2): 554-562

Frixou., G., \& Charalambous., G. (2016). Human Resources Assessment as a Component of Effective Management- Implications for the Health Sector. International Journal of Caring Sciences, 9(1): 358 
Rao, A., \& Abdul, K. W. (2015), "Impact of transformational leadership on team performance: an empirical study in UAE", Measuring Business Excellence, 19(4): 30-56. https://doi.org/10.1108/MBE-07-2014-0022

Vatankhah, S., Alirezaei, S., Khosravizadeh, O., Mirbahaeddin, S. E., Alikhani, M., \& Alipanah, M. (2017). Role of transformational leadership on employee productivity of teaching hospitals: using structural equation modeling. Electronic physician, 9(8): 4978-4984. doi:10.19082/4978

Anderson, R. A., Bailey, D. E., Wu, B., Corazzini, K., McConnell, E. S., Thygeson, N. M., Docherty, S. L. (2015). Adaptive Leadership Framework for Chronic Illness Framing a Research Agenda for Transforming Care Delivery. ANS Adv Nurs Sci, 38(2): 83-95. doi: 10.1097/ANS.0000000000000063

AlKhamees, O. A., AlNemer, K. A., Bin Maneea, M., WAlSugair, F. A., AlEnizi, B. H., \& Alharf, A. A. (2018). Top 10 most used drugs in the Kingdom of Saudi Arabia 2010-2015. Saudi Pharmaceutical Journal, 26, 211-216

Muhrer, J. C. (2017). Improving breast cancer screening in a federally qualified health center with a team of nursing leaders. The Nurse Practitioner, 42(1): 12-16

doi: 10.1097/01.NPR.0000511004.83595.16

Kennerly, S. M., Yap, T., \& Miller, E. (2012). A Nurse-Led Interdisciplinary Leadership Approach Targeting Pressure Ulcer Prevention in Long-term Care. The Health Care Manager, 31(3): 268-275

DOI: $10.1097 /$ HCM.0b013e3182619eca268

De Bono, A. G., Heling, A. M. A., \& Borg. (2014). Organizational culture and its implications for infection prevention and control in healthcare institutions. Journal of Hospital Infection, 86

Kouzes and Posner. (2011). The Five Practices, for Transformational Leadership Required to Design and Sustain Evidence-Based Practice: A System Exemplar. Western Journal of Nursing Research, 33(3): 398-426

Gusdorf, M. (2008). Recruitment and Selection: Hiring the Right Person A two-part learning module for undergraduate students Staffing Management.

Chasseignea, V., Blacheab, L., Prudhommed, N., \& Costae, K. (2018). Assessing the costs of disposable and reusable supplies wasted during surgeries.

https://doi.org/10.1016/j.ijsu.2018.02.004

Oliver, L. (2018). Cost Savings and Cost Avoidance: Why You Should Know the Difference. Retrieved from https://www.obalearn.com/cost-savings-cost-avoidance-know-difference/

Bloom, N., Sadun, R., \& Reenen, J. V. (2014). Does Management Matter in Healthcare?

Bass, B., Avolio, B. (1994). Improving organizational effectiveness through transformational leadership.

Sfantou, D., Laliotis, A., Patelarou, A., Pistolla, D., Matalliotakis, M., \& Patelarou, E. (2017). Importance of Leadership Style towards Quality of Care Measures in Healthcare Settings: A Systematic Review. Healthcare 5(73)

Retrieved from doi:10.3390/healthcare 5040073

Hamdani, M. (2018). Learning how to be a transformational leader through a skill building, Role-play exercise. The International Journal of Management Education. 16(1), 26-36. Retrieved from https://doi.org/10.1016/j.ijme.2017.11.003

Rothberg, M., Class, J., Bishop, T., Friderici, J., Kleppel, R., \& Lindenauer, P. (2014). The Cost of Defensive Medicine on Three Hospital Medicine Services. 
Retrieved from doi: 10.1001/jamainternmed.2014.4649

Cimiotti, A., Aiken, L., Sloane, D. (2012). Nurse staffing, burnout, and health care-associated infection. American Journal of Infection Control. 40(6) 486-490.

Retrieved from https://doi.org/10.1016/j.ajic.2012.02.029

Javitt, J., Aiello, L., Chiang, Y., Ferris, F., Canner, J., \& Greenfield, S. (1994). Preventive Eye Care in People With Diabetes Is Cost-Containment to the Federal Government: Implications for health-care reform. Diabetes Care. 17(8): 909-917

Retrieved from https://doi.org/10.2337/diacare.17.8.909

The Cost Containments of Investing in Chronic Disease Prevention and Health Promotion in South Dakota. (2014). Retrieved from http://goodandhealthysd.org/wpcontent/uploads/2014/01/FinalCostContainmentsWhitePaper.pdf

May, P., Garrido, M., Cassel, B., Kelley, A., \& Meier, D. (2015). Palliative Care Teams' CostContainment Effect Is Larger For Cancer Patients With Higher Numbers Of Comorbidities. Retrieved from https://doi.org/10.1377/hlthaff.2015.0752

Mehwish, M. (2018). Importance of Resource Allocation and Time Management in Project Management

Burke, L., \& Ryan, A. (2014). The Complex Relationship between Cost and Quality in US Health Care. American Medical Association Journal of Ethics 16(2): 124-130.

Waldman, D., Kelly, F., Arora, S., \& Smith, H. (2004). The Shocking Cost of Turnover in Health Care. Health Care Manage Rev, 29(1): 2-7

Badgal, A. (2015). Factors affecting the average length of stay of the patient in the inpatient department in a tertiary care center in north India. Journal of Evolution of Medical and Dental Sciences, 4(02):150-155

Rahmqvist, M., Samuelsson, A., Bastami, S., \& Rutberg, H. (2016). Direct health care costs and length of hospital stay related to health care-acquired infections in adult patients based on point prevalence measurements. American Journal of Infection Control, 44(5): 500506

Kearney, E. (2010). Age differences between leader and followers as a moderator of the relationship between transformational leadership and team performance. Journal of Occupational and Organizational Psychology. 81(4) https://doi.org/10.1348/096317907X256717

Oshagbemi, T. (2004), "Age influences on the leadership styles and behaviour of managers", Employee Relations, 26(1): 14-29. https://doi.org/10.1108/01425450410506878

Stempel, C. R., Rigotti, T., \& Mohr, G. (2015). Think transformational leadership - Think female? 11(3): 259-280

Herman, S., \& Gish, M. (2015). Effects of Nursing Position on Transformational Leadership Practices. JONA: The Journal of Nursing Administration, 45(2): 113-119 doi: 10.1097/NNA.0000000000000165

OlcumCetin, M., \& FaydaKini, S. (2015). An Analysis of Academic Leadership Behavior from the Perspective of Transformational Leadership. Procedia - Social and Behavioral Sciences, 20, 519-527 